\title{
Source process of the 2016 Kumamoto earthquake (Mj7.3) inferred from kinematic inversion of strong-motion records
}

\author{
Kunikazu Yoshida ${ }^{1 *}$, Ken Miyakoshi ${ }^{1}$, Kazuhiro Somei ${ }^{1}$ and Kojiro Irikura ${ }^{2}$
}

\begin{abstract}
In this study, we estimated source process of the 2016 Kumamoto earthquake from strong-motion data by using the multiple-time window linear kinematic waveform inversion method to discuss generation of strong motions and to explain crustal deformation pattern with a seismic source inversion model. A four-segment fault model was assumed based on the aftershock distribution, active fault traces, and interferometric synthetic aperture radar data. Three western segments were set to be northwest-dipping planes, and the most eastern segment under the Aso caldera was examined to be a southeast-dipping plane. The velocity structure models used in this study were estimated by using waveform modeling of moderate earthquakes that occurred in the source region. We applied a two-step approach of the inversions of 20 strong-motion datasets observed by K-NET and KiK-net by using band-pass-filtered strong-motion data at $0.05-0.5 \mathrm{~Hz}$ and then at $0.05-1.0 \mathrm{~Hz}$. The rupture area of the fault plane was determined by applying the criterion of Somerville et al. (Seismol Res Lett 70:59-80, 1999) to the inverted slip distribution. From the first-step inversion, the fault length was trimmed from 52 to $44 \mathrm{~km}$, whereas the fault width was kept at $18 \mathrm{~km}$. The trimmed rupture area was not changed in the second-step inversion. The source model obtained from the two-step approach indicated $4.7 \times 10^{19} \mathrm{Nm}$ of the total moment release and $1.8 \mathrm{~m}$ average slip of the entire fault with a rupture area of $792 \mathrm{~km}^{2}$. Large slip areas were estimated in the seismogenic zone and in the shallow part corresponding to the surface rupture that occurred during the Mj7.3 mainshock. The areas of the high peak moment rate correlated roughly with those of large slip; however, the moment rate functions near the Earth surface have low peak, bell shape, and long duration. These subfaults with long-duration moment release are expected to cause weak short-period ground motions. We confirmed that the southeast dipping of the most eastern segment is more plausible rather than northwest-dipping from the observed subsidence around the central cones of the Aso volcano.
\end{abstract}

Keywords: 2016 Kumamoto earthquake, Source process, Kinematic inversion, Near-fault strong motion

\section{Introduction}

The 2016 Kumamoto earthquake, with Japan Meteorological Agency (JMA) magnitude (Mj) of 7.3, occurred at 01:25 JST on April 16, 2016, following the Mj6.5 earthquake occurring at 21:26 on 14 April. During these earthquakes, a JMA intensity scale of 7 was recorded at several stations near the source faults. These abundant nearfault strong-motion records have enabled us to analyze detailed source characteristics. Many surface ruptures

\footnotetext{
*Correspondence: yoshida@geor.or.jp

${ }^{1}$ Geo-Research Institute, 2-1-2 Otemae, Chuo-ku, Osaka 540-0008, Japan Full list of author information is available at the end of the article
}

(e.g., Shirahama et al. 2016) and significant crustal deformations (e.g., Geospatial Information Authority of Japan 2016a) have been investigated for these earthquakes.

The source region of the 2016 Kumamoto earthquake is located on the Beppu-Shimabara graben system, which is situated in the central part of Kyushu Island. In this graben system which is the center of the extensional field of the central Kyushu (Tada 1984), active fault zones are well developed in a nearly east-west trend. The 2016 Kumamoto earthquakes occurred along two of these fault zones: Futagawa and Hinagu (Fig. 1).

Several source models of the Mj7.3 of the 2016 Kumamoto earthquake have been proposed on the basis of the 


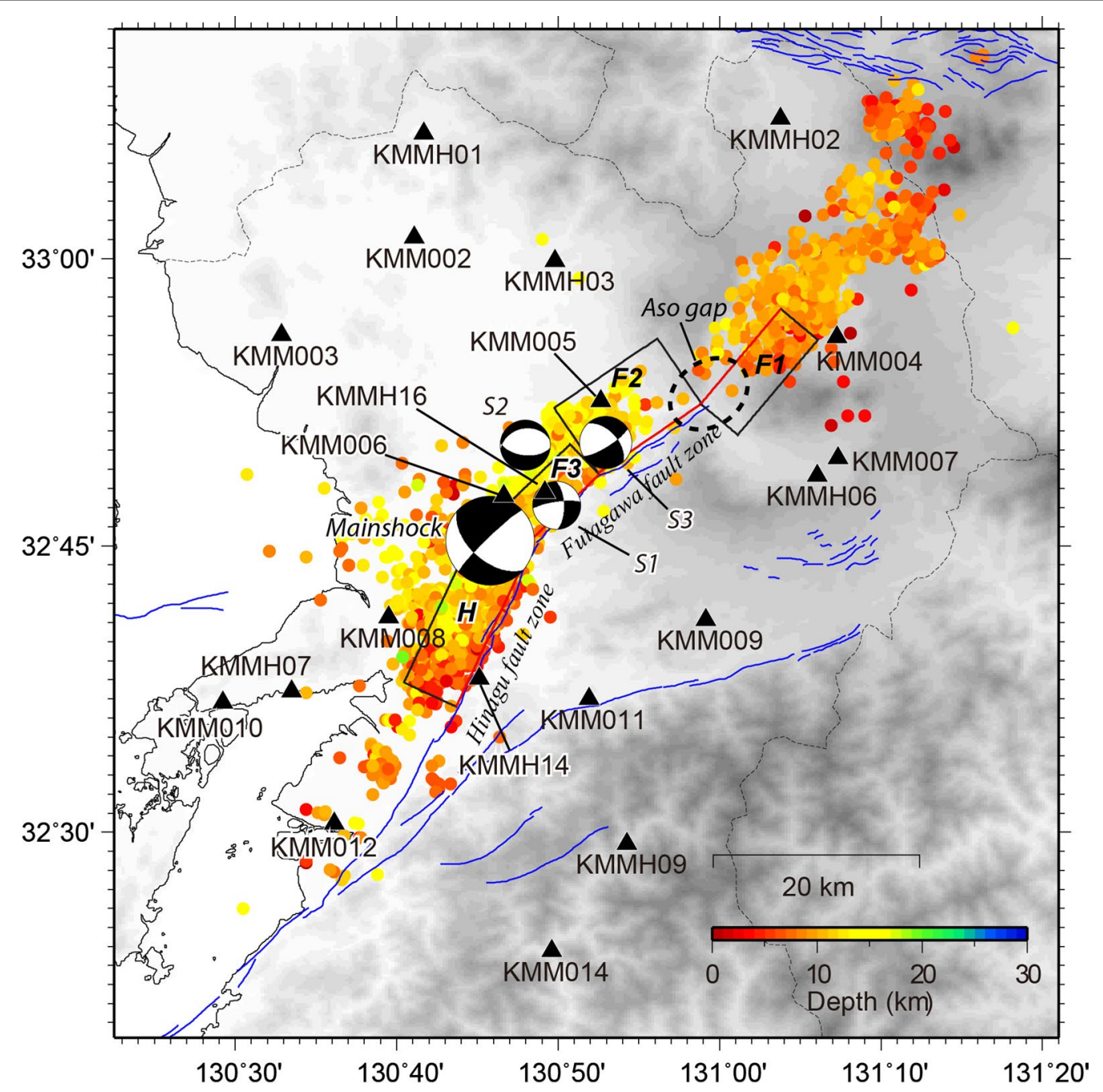

Fig. 1 Map showing aftershocks (after the JMA unified hypocenter catalogue) that occurred during the first $24 \mathrm{~h}$ after the mainshock, and the location of active faults (blue line, National Institute of Advanced Industrial Science and Technology 2012). Triangles show the seismic stations used in this study. The moment tensor solutions of the mainshock and the moderate earthquakes (S1:4/21 21:52 Mw3.9, S2: 4/20 16:01 Mw4.0 and S3:4/15 15:27 Mw4.2) used in this study shown at the rupture starting point. The solutions are determined by NIED with F-net data. The surface projection of our four-segment initial fault model is shown by a rectangle. F1, F2, F3, and $H$ indicate segment names. The top edge of the segment is indicated by the red line

strong motions (e.g., Asano and Iwata 2016), teleseismic waveforms (Yagi et al. 2016), and crustal deformation (e.g., Himematsu and Furuya 2016). Most of these studies based on seismic data assume northwest-dipping fault planes. However, several studies based on the crustal deformation data obtained by interferometric synthetic aperture radar (InSAR) and global navigation satellite system (GNSS) networks suggest a southeast-dipping fault mechanism in the Aso caldera region (e.g., Ozawa et al. 2016). Determining the fault plane dip direction based on the aftershock distribution is difficult because of the seismicity gap in the western part of the Aso caldera region
(Aso gap in Fig. 1, Uchide et al. 2016). Although we have previously proposed a source model with a northwestdipping fault model using strong-motion data (Irikura et al. 2017), it is important to rediscuss a source model with a southeast-dipping fault model based on strong motion.

In this study, we infer the rupture process of the mainshock of the 2016 Kumamoto earthquake by applying the multiple-time window linear kinematic waveform inversion method to strong-motion data. In order to obtain detailed source models, velocity structure models are improved by using waveform modeling of moderate 
earthquakes that occurred near the mainshock. We discuss behavior of rupture near the Earth surface by using total slip and moment rate functions. Moreover, we compare the crustal deformations calculated from the inverted source model with those observed by InSAR.

\section{Fault model}

An assumed fault model consists of four segments based on the aftershock distribution, active fault traces (Nakata and Imaizumi 2002; National Institute of Advanced Industrial Science and Technology 2012), and observation from InSAR (Geospatial Information Authority of Japan 2016a). This earthquake occurred along two known fault zones: Hinagu and Futagawa (Fig. 1). Four segments of different strike and dip (Table 1) were defined to represent curved fault systems: segment $\mathrm{H}$ along the Hinagu fault zone, segment F3 along a plane connecting the Futagawa and Hinagu fault zones, and segments F2 and F1 along the Futagawa fault zone, as shown in Fig. 1. H, F3, and F2 segments were set to be northwest dipping based on the aftershock distribution. In our previous paper (Irikura et al. 2017), we assumed a different four-segment model with a northwest-dipping F1 segment. In the present study, we examined the four-segment model with a southeast-dipping F1 segment because subsidence of the vertical deformation around the central cones of the Aso volcano observed by InSAR and GNSS data suggests that the segment dips in that direction. The rupture starting point is located at the hypocenter determined by the JMA unified hypocenter.

\section{Velocity structure model}

In order to obtain accurate Green's functions, we determine a 1D stratified velocity models for each station, inverting waveforms of small events. Several previous studies (Ichinose et al. 2003; Hikima and Koketsu 2005; Asano and Iwata 2009) constructed proper layered structure models to individual stations based on the waveform modeling of small events and succeeded in obtaining a detailed source rupture process.

The waveform inversion method is a downhill simplex method (Nelder and Mead 1965) for the Earth structure, which was parameterized as a layered medium with P- and S-wave velocities. The initial model (Fig. 2) was taken from the structure at the site location of the J-SHIS model (Fujiwara et al. 2012), microtremor array survey (Yoshida et al. 2016), and PS-logging. The objective function was defined by

$$
f=\sum_{i=1}^{M}[O(i)-C(i)]^{2} / \sum_{i=1}^{M} O(i)^{2}+p,
$$

Table 1 Initial model parameters of fault planes assumed in the waveform inversion

\begin{tabular}{lllll}
\hline Segment & Length $(\mathbf{k m})$ & Width $(\mathbf{k m})$ & Strike $\left(^{\circ}\right)$ & Dip $\left(^{\circ}\right)$ \\
\hline F1 & 12 & 18 & N40E (N220E) & $75(105)$ \\
F2 & 12 & 18 & N236E & 65 \\
F3 & 12 & 18 & N226E & 77 \\
H & 16 & 18 & N205E & 72 \\
\hline
\end{tabular}

Reversed strike and dip angles of the F1 segment are also shown in addition to the conventional dip angle $\left(0^{\circ}-90^{\circ}\right)$ and strike

where $i$ is time, $M$ is the number of sample, $C(i)$ is a synthetic seismogram calculated using the discrete wave number method (Bouchon 1981) and the reflection/ transmission coefficient matrix method (Kennett and Kerry 1979), and $O(i)$ is the observed seismogram. A penalty parameter $p$, which constrains the $\mathrm{P}$ - to $\mathrm{S}$-wave velocity $\left(V_{\mathrm{P}} / V_{\mathrm{S}}\right)$ ratio, is defined by

$$
p=\gamma \sum_{j=1}^{L}\left(\alpha_{j} / \alpha_{j}^{\prime}-1\right)^{2},
$$

where $\alpha_{j}$ is the $\mathrm{P}$-wave velocity at layer $j$; $\alpha_{j}^{\prime}$ is the $\mathrm{P}$-wave velocity calculated from the $\mathrm{S}$-wave velocity at layer $j$ using the empirical P- and S-wave velocity relation, which was derived from deep borehole logging data in Japan (Kitsunezaki et al. 1990); and $\gamma$ is the weight of the constraint, which in this study was 0.01 .

Velocity structure models of the 20 sites were inverted with fixed point source parameters and layer thicknesses using strong-motion data from three moderate-magnitude earthquakes within the rupture area of the main shock (S1, S2, and S3 in Fig. 1). The target acceleration seismograms were band-pass-filtered between 0.3 and $1.0 \mathrm{~Hz}$ and were integrated into velocities. The focal mechanism and seismic moment provided by F-net were used. The inverted velocity structure models are shown in Fig. 2.

In order to examine the appropriateness of the inverted velocity structure model, we simulated the waveforms of the S1 (Mw3.9) and S3 (Mw4.2) earthquakes (Fig. 1) assuming a point source with a rise time of $0.7 \mathrm{~s}$. The observed and synthetic velocity waveforms band-pass-filtered between 0.3 and $1 \mathrm{~Hz}$ are compared in Fig. 3a. The synthetic waveforms using the inverted velocity structure models shown in Fig. 2 reasonably explain the observed waveforms. For example, agreement of the $\mathrm{S}$-wave amplitude and travel time between the observations and the synthetics calculated from the inverted model at KMM008 was better than the ones of the initial model (Fig. 3b). At KMMH16, the velocity model inversion 


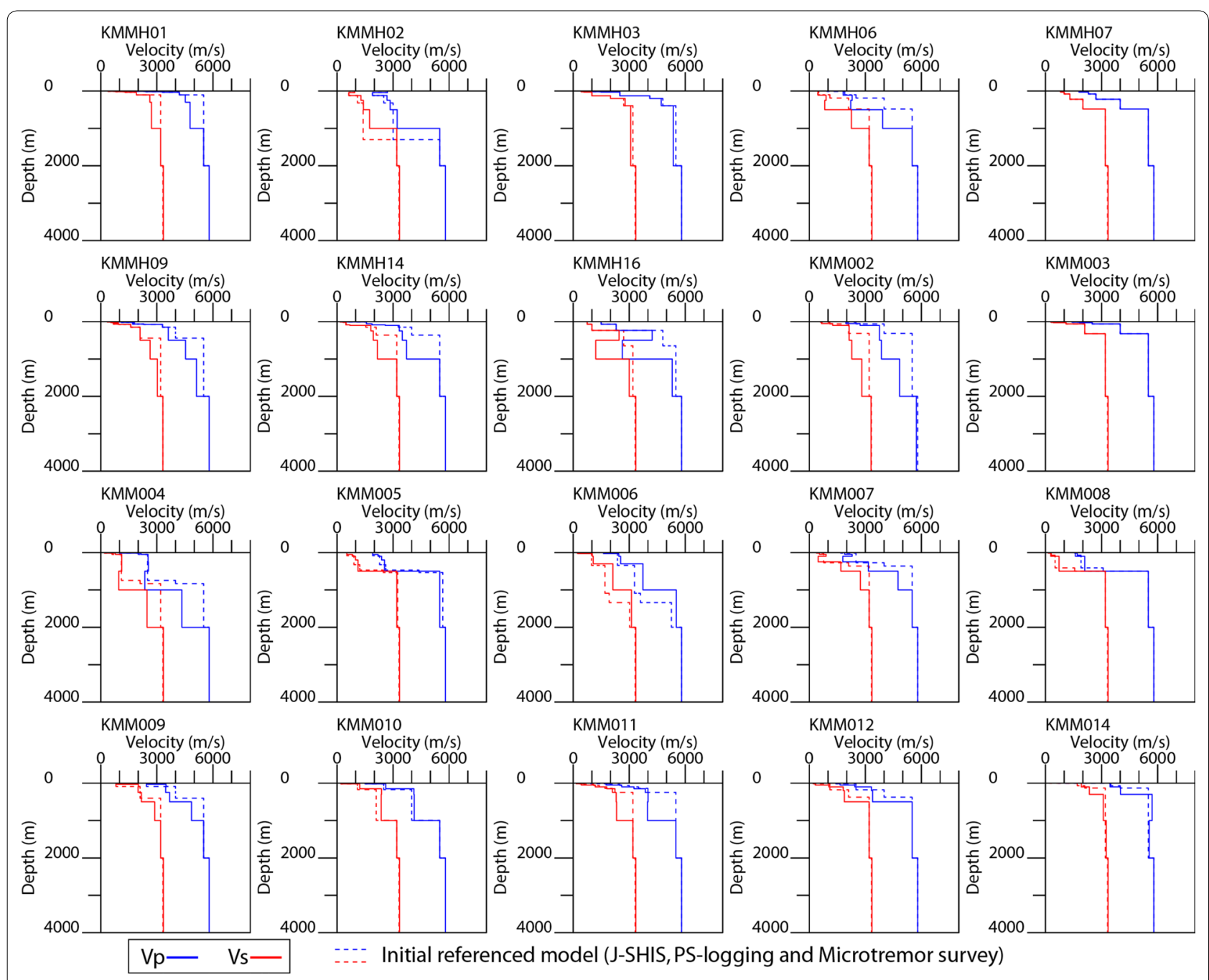

Fig. 2 Estimated velocity structure model (solid line) and initial velocity model (broken line). The microtremor array survey was operated at KMM005, KMM006, and KMM008 (Yoshida et al. 2016)

slightly improved the agreement of $\mathrm{S}-\mathrm{P}$ times between the synthetic data and the observations (Fig. 3c).

\section{Estimation of source process}

We applied a two-step approach of the multi-time window linear waveform inversions of strong-motion data (Hartzell and Heaton 1983) to estimate the rupture process for the fault model. First, the slip distribution was inverted using the $0.05-0.5 \mathrm{~Hz}$ band-pass strong-motion data. The proper rupture area of the earthquake was estimated applying the trimming criterion of Somerville et al. (1999) into the derived slip model. Second, the slip distribution was reanalyzed from the $0.05-1.0 \mathrm{~Hz}$ waveform inversion of strong-motion data including higherfrequency motions for the reduced fault plane in order to estimate the detailed rupture process.

We used near-fault strong-motion data obtained from 20 stations of K-NET and KiK-net (borehole data); their structures were estimated in the previous section. The data were windowed for $27 \mathrm{~s}$, starting at the P-wave

Fig. 3 Comparison of the observed velocities (Obs.), the synthetic velocities for the derived model (Inv.), and the synthetic velocities for the reference (initial) model (Ref.) of moderate earthquakes $(0.3-1.0 \mathrm{~Hz})$. The number at the upper right of each wave indicates the maximum amplitude of the observed waveforms. a S1 event at all stations. Time since the event origin is shown. b Zoomed view of KMM008. c S3 event at KMMH16. Waveforms in this panel are aligned to P-wave arrival to compare the S-P time 


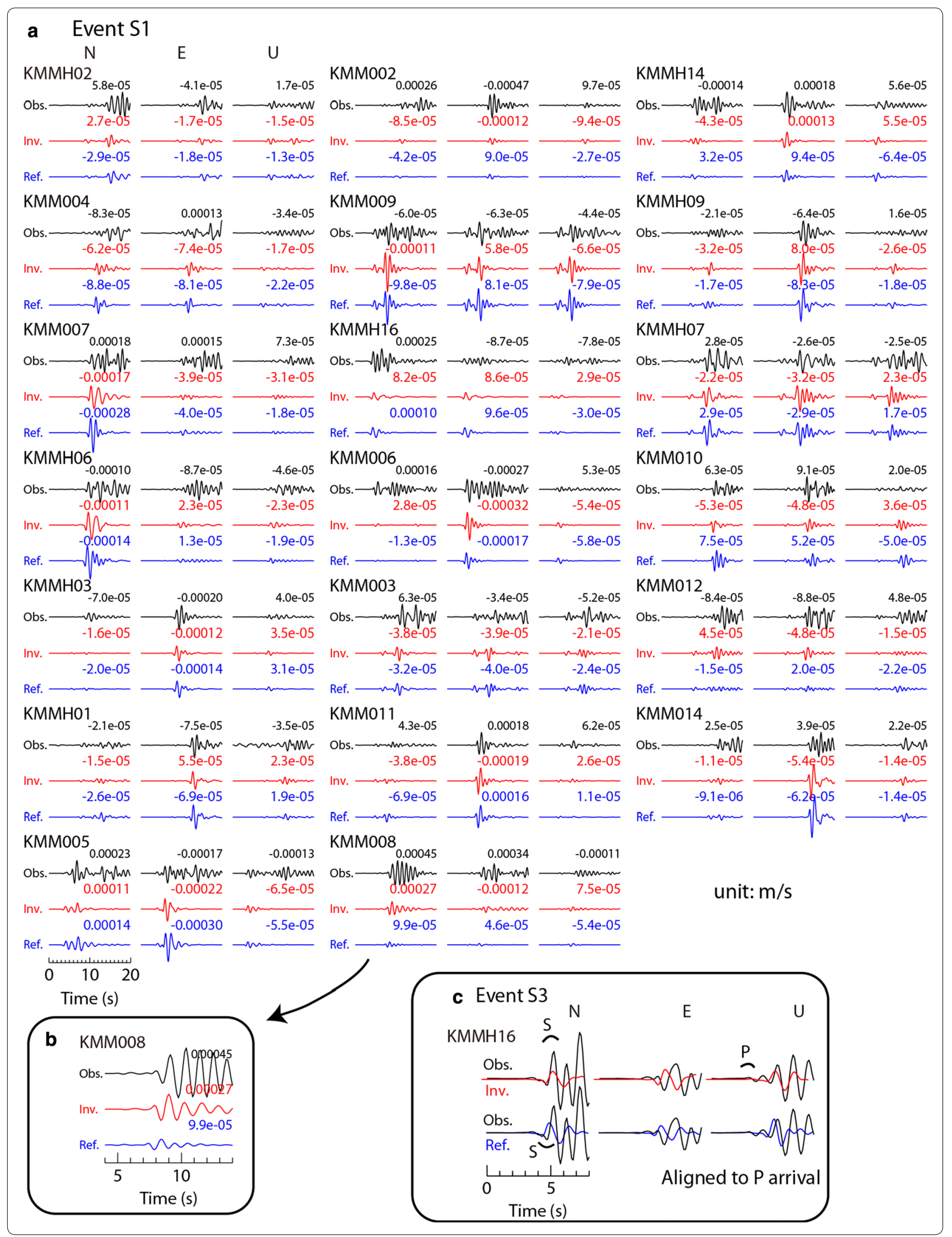


arrival time, and were band-pass-filtered with the respective passband. The accelerograms were integrated into ground velocities, and the data were then resampled with the frequency of $8 \mathrm{~Hz}$.

Theoretical Green's functions were calculated by using the discrete wave number method (Bouchon 1981) and the reflection/transmission coefficient matrix method (Kennett and Kerry 1979) using the velocity structure models estimated in the previous section (Fig. 2). In the multi-time window linear waveform inversion procedure, the moment release distribution is discretized in both space and time. The fault plane was divided into 13 (along strike) $\times 9$ (along dip) subfaults with a size of $4 \mathrm{~km}$ (along strike) $\times 2 \mathrm{~km}$ (along dip) for the first step. We distributed 15 point sources at a $0.8 \mathrm{~km}$ (strike) by $0.67 \mathrm{~km}$ (dip) interval inside each subfault to consider the rupture propagation effect (e.g. Wald et al. 1991). For the moment rate functions at individual subfaults, we aligned smoothed ramp functions having durations of $1.8 \mathrm{~s}$ at intervals of $0.9 \mathrm{~s}$ in the first step and those of $0.9 \mathrm{~s}$ at intervals of $0.45 \mathrm{~s}$ in the second step to represent the moment release of each subfault. Non-negative constraints (Lawson and Hanson 1974) were also adopted to limit the rake angle variation. The rake angles were allowed to vary within $\pm 45^{\circ}$ centered at $180^{\circ}$.

The weight of the smoothing constraint for inversion with a certain first-time window propagating velocity $\left(V_{\mathrm{FT}}\right)$ value was determined on the basis of Akaike's Bayesian information criterion (ABIC) proposed by Akaike (1980) following previous studies (e.g. Sekiguchi et al. 2000). The number of smoothed ramp functions representing moment release was also determined on the basis of ABIC.
Figure 4 shows the total slip distribution of the firststep inversion using $0.05-0.5 \mathrm{~Hz}$ band-pass strongmotion data. The total moment release was $6.7 \times 10^{19}$ $\mathrm{Nm}$, and the average slip of the entire fault was $2.3 \mathrm{~m}$. The number of smoothed ramp functions was determined to be 4 , which allows a maximum of $4.5 \mathrm{~s}$ moment releases for each subfault. The slip distribution showed mainly a strike-slip fault mechanism.

We applied the trimming criterion of Somerville et al. (1999) to remove columns of their average slip below 0.3 times the average slip of the entire fault $(0.69 \mathrm{~m}$ in this study) from our slip model in order to estimate the proper rupture area of the earthquake. The trimming result removed two columns $(8 \mathrm{~km})$ of the southwest edge of the fault plane as shown in Fig. 4. The reduction in moment release was $4 \%$, at $6.7 \times 10^{19}$ to $6.5 \times 10^{19}$ $\mathrm{Nm}$.

The second-step inversion of $0.05-1.0 \mathrm{~Hz}$ strongmotion data with the trimmed rupture area was then conducted; the result is shown in Fig. 5. For this inversion analysis, seven smoothed ramp functions were assumed for each subfault. Table 2 summarizes the inversion result. The total moment release was $4.7 \times 10^{19} \mathrm{Nm}$, and the estimated average slip of the entire fault was $1.8 \mathrm{~m}$. $V_{\mathrm{FT}}$ was searched in the range of $1.8-3.2 \mathrm{~km} / \mathrm{s}$ with an interval of $0.2 \mathrm{~km} / \mathrm{s}$ and was determined to be $2.2 \mathrm{~km} / \mathrm{s}$ by the minimum ABIC. The slip distribution showed mainly a strike-slip; however, a normal slip also appeared on the F2 segment. This slip distribution is very similar to that of our previous study assuming a northwest-dipping F1 segment (Irikura et al. 2017). Figure 6 displays a comparison between the observed and synthetic velocity waveforms. In appearance, the synthetic waveforms agreed well with

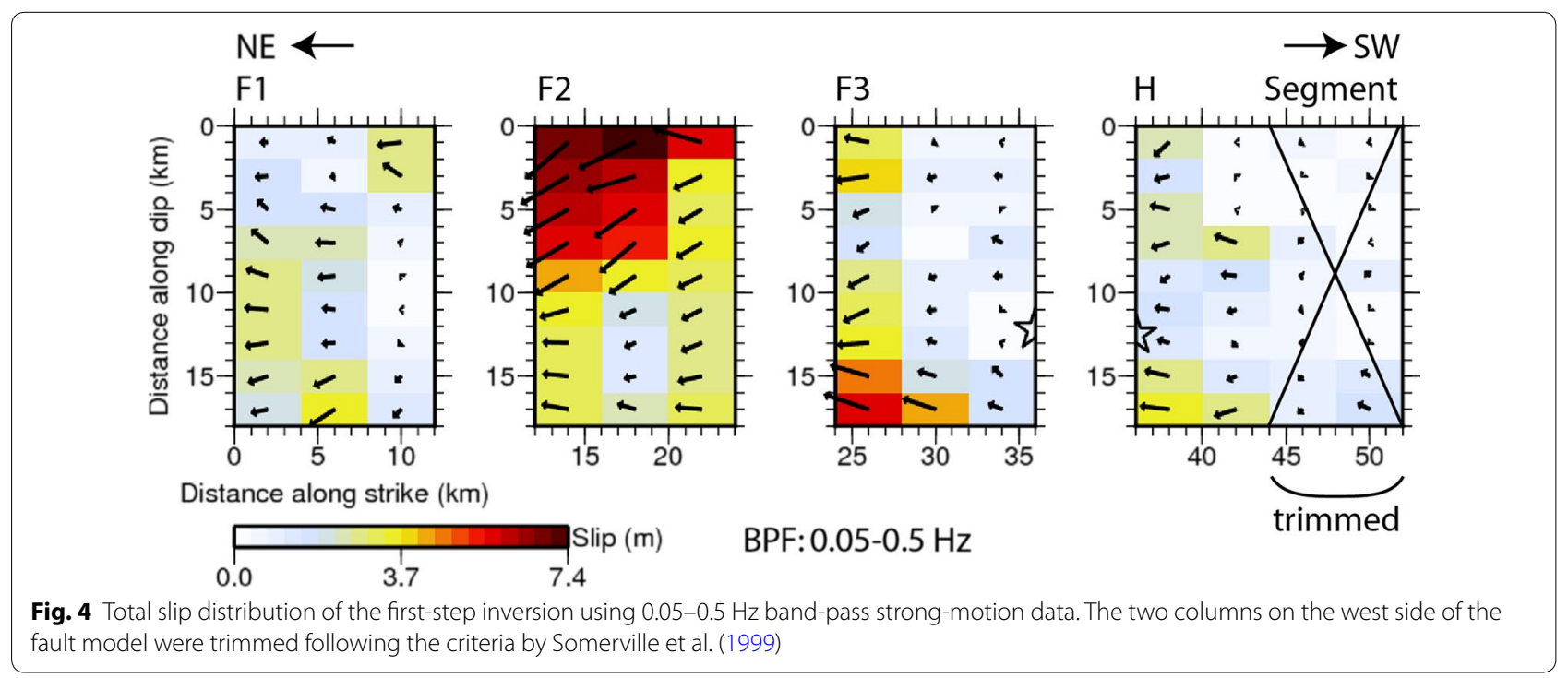



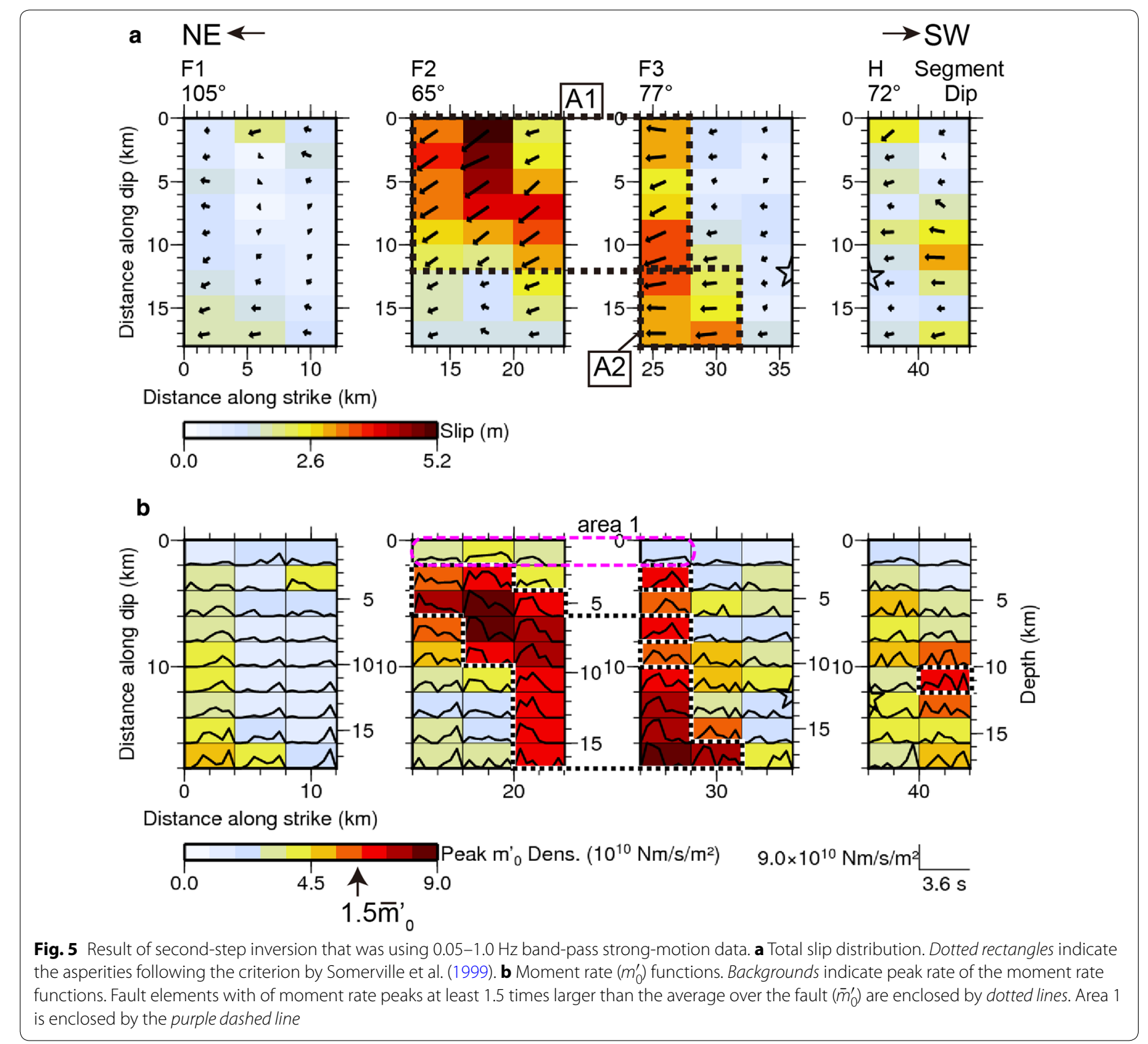

Table 2 Estimated fault parameters

\begin{tabular}{ll}
\hline & Entire fault \\
\hline Total moment $(\mathrm{Nm})$ & $4.7 \times 10^{19}$ \\
Mw & 7.1 \\
Max. slip (m) & 5.2 \\
Average slip (m) & 1.8 \\
Trimmed fault area $\left(\mathrm{km}^{2}\right)$ & $44 \times 18=792$ \\
Initial fault area $\left(\mathrm{km}^{2}\right)$ & $52 \times 18=936$ \\
Combined asperity area $\left(\mathrm{km}^{2}\right)$ & 240 \\
First-time window velocity $(\mathrm{km} / \mathrm{s})$ & 2.2 \\
\hline
\end{tabular}

the observed ones surrounding the source faults. In particular, the synthetic strong motions of KMMH16 (KiKnet Mashiki), which is located very close to the fault, effectively explain the observed motions with the largest velocity during the earthquake.

We examined the resolution of the dataset by using a checkerboard test. We generated a synthetic dataset for the checkerboard-like slip distributions shown in Fig. 7a. The moment rate functions on the subfaults of this checkerboard source model were a single smoothed ramp function with a rise time of $0.9 \mathrm{~s}$. The start of the moment 


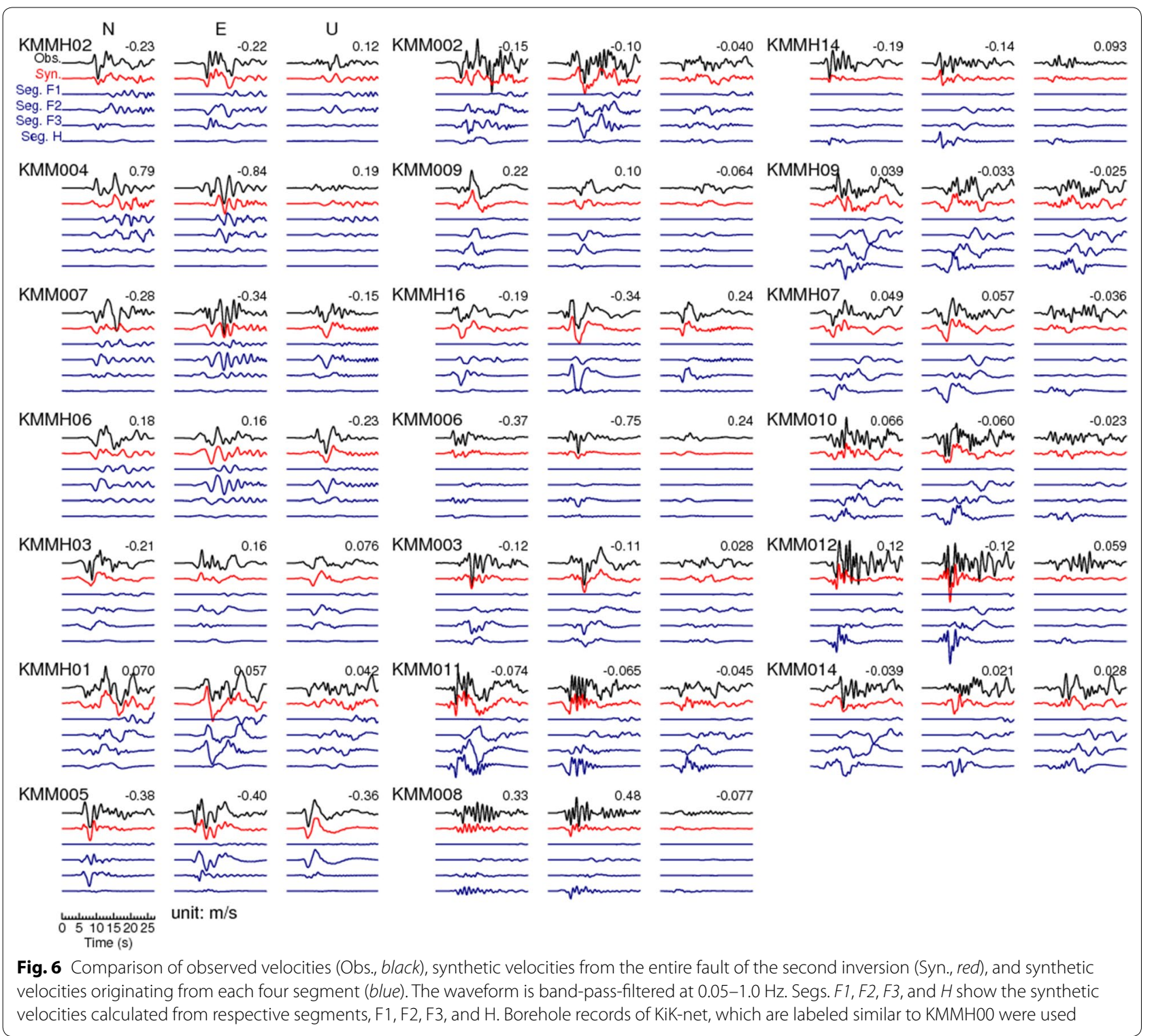

release propagated with $2.2 \mathrm{~km} / \mathrm{s}$ from the rupture starting point of the mainshock. Noise was not added to the synthetic dataset. The synthetic dataset was inverted by using the same parameters as those for the second-step inversions including smoothing, $2.2 \mathrm{~km} / \mathrm{s}$ of $V_{\mathrm{FT}}$, seven time windows with $0.45 \mathrm{~s}$ intervals, a smoothed ramp function of $0.9 \mathrm{~s}$ in duration, $27 \mathrm{~s}$ data length, the bandpass filtering of $0.05-1.0 \mathrm{~Hz}$, and selected stations. Figure $7 \mathrm{~b}$ shows the results of the checkerboard test. The overall spatial resolution of the inversion was sufficient for discussing the rupture process; however, some low resolution was seen on the F1 segment.

The contributions of each segment on the ground motions (Fig. 6) showed that the F1 segment did not dominate the ground motions of the stations even around the F1 segment (KMMH02, KMMH06, KMM004, and KMM007), whereas the F2, F3, and $\mathrm{H}$ segments controlled the ground motions at the stations around the respective segments (e.g., KMMH14 and KMMH16). The dominance of the F2, F3, and H segments on the ground motions contributed to the good resolution of the inverted solutions on these segments. In contrast, the ground motions at the stations close to the F1 segment appeared to be not controlled by the contribution of the F1 segment; its contribution on the ground motions was largest at KMM004 but was not larger than that from the F2 segment. Therefore, the solution for the F1 segment of the inverted source model is not well constrained by the ground motion data used in this study. This weak constraint corresponds to the apparently low resolution 

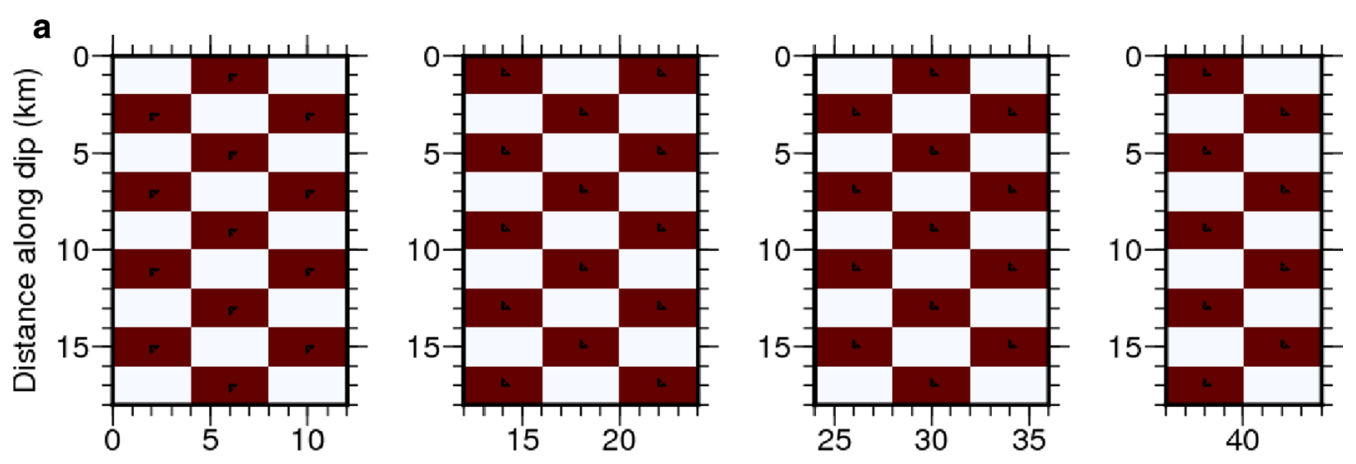

Distance along strike (km)
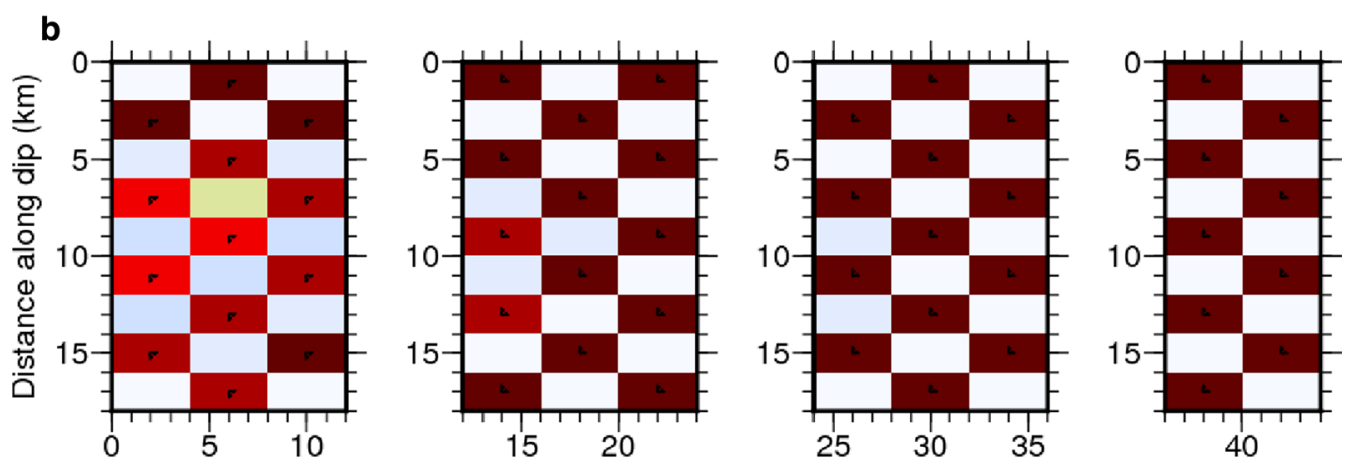

Distance along strike $(\mathrm{km})$

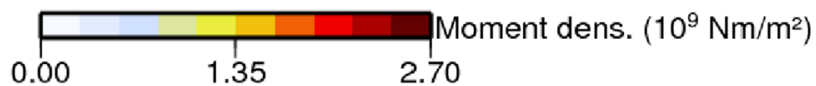

Fig. 7 a Target model used in the checkerboard resolution tests (moment densities of $0 \mathrm{Nm} / \mathrm{m}^{2}$ and $2.7 \times 10^{9} \mathrm{Nm} / \mathrm{m}^{2}$ ). b Result of the checkerboard resolution test

on the F1 segment shown in the results of checkerboard test (Fig. 7b). That is, the uncertainty of the F1 segment weakly affected the makeup of the synthetic waveforms from the entire fault.

\section{Discussion}

Two asperities were determined from the total slip distribution by using the procedure of Somerville et al. (1999). The major asperity, the A1 asperity, is identified at a depth between $0.5 \mathrm{~km}$ at the top of the fault plane and $10 \mathrm{~km}$ on the F2 and F3 segments of the fault (Fig. 5a). Another minor asperity, the A2 asperity, was identified on the deep part of the F3 segment. The A1 asperity, at the depth of $0.5 \mathrm{~km}$, corresponded to the location of the surface ruptures during the earthquake (e.g., Shirahama et al. 2016). The proper rupture area $S$, at $792 \mathrm{~km}^{2}$, and the combined asperity area $S_{\mathrm{a}}$, at $240 \mathrm{~km}^{2}$, agree with the scaling relations of $S-M_{0}$ and $S_{\mathrm{a}}-M_{0}$ (Irikura and Miyake 2001, Miyakoshi et al. 2015) for the seismic moment $M_{0}$.

The moment rate functions of subfaults in the deeper part of the A1 asperity have Kostrov-type function
(Kostrov 1964), short duration, and high peak moment rate (PMR), whereas those in the shallower part of the A1 asperity (area 1) have bell-like shape, long-duration function, and low PMR (Fig. 5b). The bell shape of the moment rate functions in area 1 is expected to cause weak short-period ground motions owing to low peak of the bell shape moment rate function. Long duration of the moment rate function near the Earth surface has been pointed out in previous studies of the 1995 Hyogoken Nanbu earthquake (Sekiguchi et al. 1996) and the 2014 North Nagano earthquake (Hikima et al. 2015).

The PMR distribution shown in Fig. 5b was used to investigate the generation areas of the strong motions. Fault elements with PMRs of at least 1.5 times larger than the average PMRs over the entire fault are enclosed by dotted lines in the figure; this criterion is similar to Somerville's criterion. The PMR at each subfault was calculated from the maximum moment release of all time windows except that of the last time window. In most cases, a large moment release at the last time window was suggested to be errors owing to uncertainties in the inversion analysis. 


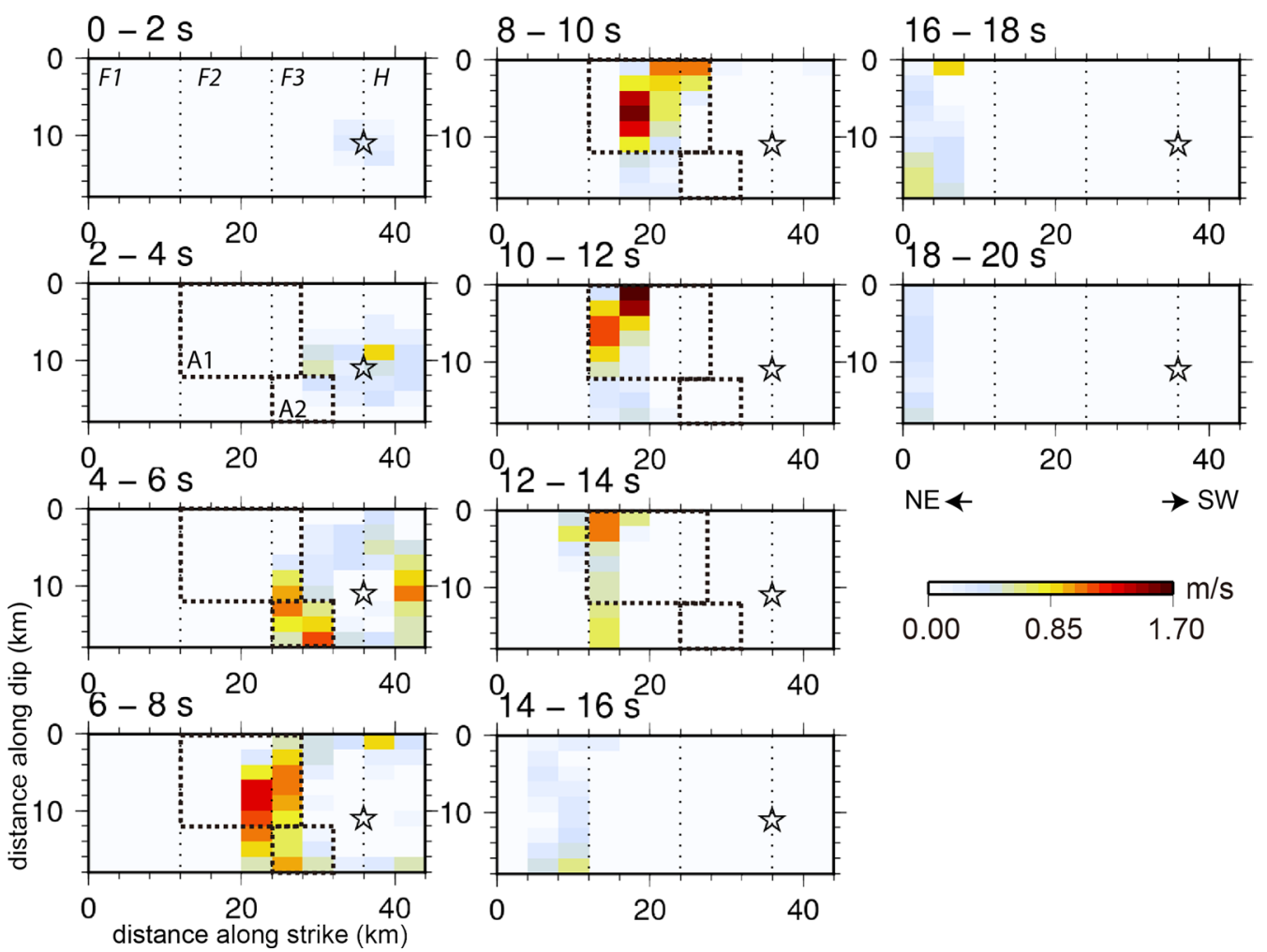

Fig. 8 Snapshot of the rupture progress in terms of slip velocity at 2-s intervals. Stars indicate the rupture starting point. The number at the top of each frame shows the time after the start of the rupture

The high PMR subfaults generally overlap with the identified asperity except in area 1 at depths $<2 \mathrm{~km}$ (Fig. 5b). The low PMR of the near-Earth surface subfault suggests that generation of strong motion from this depth is weak. The depth difference in the moment rate function implies different constitutive relations of friction between the shallow and the deeper parts (e.g., Ide and Takeo 1997).

Time progression of the rupture (Fig. 8) showed that rupture of the A1 asperity progressed upward. Frame 4-6 s indicates that the A2 asperity ruptured downward and that the $\mathrm{A} 1$ asperity began to rupture at the deeper side. Frame 6-8 s and subsequent frames show that the rupture of the A1 asperity progressed upward and reached the top of the fault plane, at the Earth surface.

We calculated the static displacements in an elastic half space (Okada 1992) from the total slip distribution of our second source model (Fig. 9a). The overall pattern of the calculated displacements agreed well with the quasi-vertical displacements (Fujiwara et al. 2000) obtained from the 2.5-D analysis of the InSAR data (Fig. 9b, Geospatial Information Authority of Japan 2016b), despite the inversion of non-geodetic data.
We also calculated the static displacements from our previous model with northwest-dipping F1 segment (Irikura et al. 2017, in which segment 4 corresponds the F1 segment in the present paper). The resulting total slip and the synthetic seismic velocity waveforms from the previous model were nearly consistent with the results of the present model. The consistency of the synthetic seismic velocity waveforms between both models suggests that the dip angle of the F1 segment is not well constrained from the sparse seismic data near the fault used in this study. However, the calculated vertical static displacements for the present southeast-dipping F1 model (Fig. 9a) and the previous northwest-dipping F1 model (Fig. 9c) clearly show different polarity on the east of the F1 segment. The vertical displacements calculated from the southeast-dipping F1 model are consistent with the subsidence around the central cones of Aso volcano obtained from the 2.5-D InSAR analysis (Fig. 9b). Ozawa et al. (2016) also explained the crustal deformation obtained from InSAR and GNSS data with a southeast-dipping fault model similar to our southeast-dipping F1 segment model. Our present fault model (Fig. 9a) explains both the strong motions and the observed subsidence around the central cones of Aso volcano. 

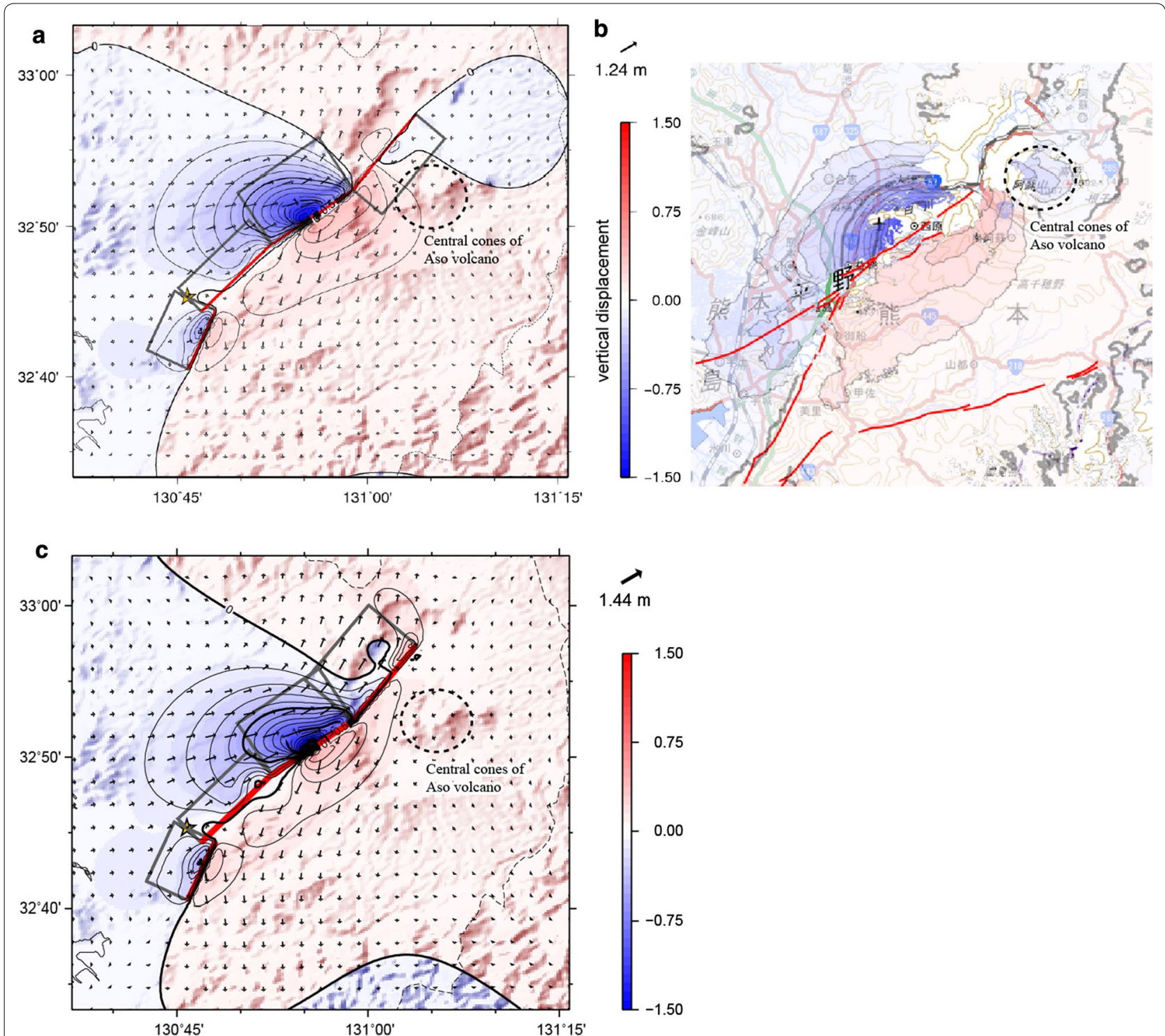

Fig. 9 a Calculated static displacements from the total slip distribution of the kinematic source model. Colors and contours indicate vertical displacements. The arrow indicates horizontal displacement. Assumed fault planes are indicated by rectangles with red lines showing the upper edge of the fault. b Observed quasi-vertical displacement obtained from InSAR data (Geospatial Information Authority of Japan 2016b). c Calculated static displacements from our previous source model with a northwest-dipping F1 segment (Irikura et al. 2017)

\section{Conclusions}

The source process of the 2016 Kumamoto earthquake was investigated from the near-fault strong-motion records by applying a two-step approach of the inversion with different frequency ranges to discuss generation of strong motions and to explain crustal deformations. Four segments, F1, F2, F3, and H, were set as the fault model consisting of segment $\mathrm{H}$ along the Hinagu fault zone, segment F3 along a plane connecting the Futagawa and Hinagu fault zones, and segments F2 and F1 along the Futagawa fault zone. Three western segments, $\mathrm{H}, \mathrm{F} 3$, and F2, were northwest-dipping, and the most eastern segment (F1) under the Aso caldera was set to be southeast-dipping. The fault size was determined to be $44 \mathrm{~km} \times 18 \mathrm{~km}\left(792 \mathrm{~km}^{2}\right)$ by the first-step inversion result of $0.05-0.5 \mathrm{~Hz}$ strong-motion data. The secondstep inversion result of $0.05-1.0 \mathrm{~Hz}$ strong-motion data indicated $4.7 \times 10^{19} \mathrm{Nm}$ for the total moment release and $1.8 \mathrm{~m}$ average slip for the entire fault. The combined area $\left(S_{\mathrm{a}}\right)$ of two asperities estimated around the shallow and deep parts of the fault was $240 \mathrm{~km}^{2}$, which agrees with the scaling relationship $S_{\mathrm{a}}$ versus $M_{0}$ reported by Irikura and Miyake (2001). The asperity area was estimated in the seismogenic zone and in the shallow part of the fault 
plane. The distribution of the high peak moment rate area correlated with the deeper part of the asperity but not near-surface part. The moment rate functions near the Earth surface had low peak, bell shape, and long duration. These long-duration subfaults are expected to cause weak short-period ground motions. The location of the shallow asperity with large slip corresponds to the locations of the observed surface rupture (e.g., Shirahama et al. 2016). The overall patterns of vertical static displacements calculated from the derived source model agree with those of the observed ones acquired by InSAR. The subsidence of the static displacement on the east of the F1 segment supports the southeast-dip of the F1 segment.

\section{Abbreviations}

ABIC: Akaike's Bayesian information criterion; GNSS: global navigation satellite system; InSAR: interferometric synthetic aperture radar; JMA: Japan Meteorological Agency; PMR: peak moment rate.

\section{Authors' contributions}

KY led and designed the entire research and drafted the manuscript. KM, KS and $\mathrm{KI}$ contributed to the discussion of the results. All authors discussed the results and commented on the manuscript. All authors read and approved the final manuscript.

\section{Author details}

1 Geo-Research Institute, 2-1-2 Otemae, Chuo-ku, Osaka 540-0008, Japan.

2 Disaster Prevention Research Center, Aichi Institute of Technology, 1247 Yachigusa, Yakusa-cho, Toyota, Aichi 470-0392, Japan.

\section{Acknowledgements}

The authors thank National Research Institute for Earth Science and Disaster Resilience (NIED) for providing K-NET and KiK-net data. F-net mechanism solutions were also provided by NIED. This study was based on the 2016 research project "Examination for uncertainty of strong ground motion prediction" by the Nuclear Regulation Authority (NRA), Japan. The authors also acknowledge valuable comments provided by Haruo Horikawa, Peter Martin Mai, and two anonymous reviewers.

\section{Competing interests}

The authors declare that they have no competing interests.

\section{Publisher's Note}

Springer Nature remains neutral with regard to jurisdictional claims in published maps and institutional affiliations.

Received: 1 August 2016 Accepted: 25 April 2017

Published online: 03 May 2017

\section{References}

Akaike H (1980) Likelihood and the Bayes procedure. In: Bernardo JM, DeGroot $\mathrm{MH}$, Smith AFM (eds) Bayesian statistics. University Press, Valencia, pp 143-166

Asano K, Iwata T (2009) Source rupture process of the 2004 Chuetsu, MidNiigata prefecture, Japan, earthquake inferred from waveform inversion with dense strong-motion data. Bull Seismol Soc Am 99:123-140

Asano K, Iwata T (2016) Source rupture processes of the foreshock and mainshock in the 2016 Kumamoto earthquake sequence estimated from the kinematic waveform inversion of strong motion data. Earth Planets Space 68:147. doi:10.1186/s40623-016-0519-9

Bouchon M (1981) A simple method to calculate Green's functions for elastic layered media. Bull Seismol Soc Am 71:959-971
Fujiwara S, Nishimura T, Murakami M, Nakagawa H, Tobita M, Rosen PA (2000) 2.5-D surface deformation of M6.1 earthquake near Mt Iwate detected by SAR interferometry. Geophys Res Lett 27:2049-2052

Fujiwara H, Kawai S, Aoi S, Morikawa N, Senna S, Azuma H, Ooi M, Hao KX, Hasegawa N, Maeda T, Iwaki A, Wakamatsu K, Imoto M, Okumura T, Matsuyama H, Narita A (2012) Some improvements of seismic hazard assessment based on the 2011 Tohoku earthquake. Technical note of the National Research Institute for Earth Science and Disaster Prevention, No. 379

Geospatial Information Authority of Japan (2016a) Information about 2016 Kumamoto earthquake, http://www.gsi.go.jp/BOUSAI/H27-kumamotoearthquake-index.html. Accessed 28 July 2016

Geospatial Information Authority of Japan (2016b) http://maps. gsi.go.jp/\#10/32.773997/130.904846/\&base=std\&ls=std\%7C urgent_earthquake_20160414kumamoto_p023dr_p135ar qu_25d\%2C0.7\%7Ctoshiken_katsudansouzu\%7C20160414kumamoto_ epicenter\%7C_20160414kumamoto_epicenter\%7Curgent_earthquake_ qugrd_cont $10 \mathrm{~cm}$ _cut $10 \% 2 \mathrm{C} 0.7 \&$ disp $=1111111 \mathrm{l} \mathrm{cd}=$ toshiken_katsudans ouzu\&vs=c1jolou0f1\&d=vl. Accessed 30 Nov 2016

Hartzell SH, Heaton TH (1983) Inversion of strong ground motion and teleseismic waveform data for the fault rupture history of the 1979 Imperial Valley, California, earthquake. Bull Seismol Soc Am 73:1553-1583

Hikima K, Koketsu K (2005) Rupture processes of the 2004 Chuetsu (mid-Niigata prefecture) earthquake, Japan: a series of events in a complex fault system. Geophys Res Lett 32:L18303

Hikima K, Nakamura R, Uetake T (2015) Source process of the 2014 NaganoKen Hokubu Earthquake (M;6.7) —analysis using the near-field Broadband Waveforms in the source region. In: proceedings of the Seismological Society of Japan Fall meeting, S15-14 (in Japanese)

Himematsu Y, Furuya M (2016) Fault source model for the 2016 Kumamoto earthquake sequence based on ALOS-2/PALSAR-2 pixel-offset data: evidence for dynamic slip partitioning. Earth Planets Space 68:169. doi:10.1186/s40623-016-0545-7

Ichinose GA, Thio HK, Somerville PG, Sato T, Ishii T (2003) Rupture process of the 1944 Tonankai earthquake (Ms 8.1) from the inversion of teleseismic and regional seismograms. J Geophys Res 108:2497

Ide S, Takeo M (1997) Determination of constitutive relations of fault slip based on seismic wave analysis. Jour Geophys Res 102:27379-27391

Irikura K, Miyake H (2001) Prediction of strong ground motions for scenario earthquakes. J Geol 110:849-875 (in Japanese with English abstract)

Irikura K, Miyakoshi K, Kamae K, Yoshida K, Somei K, Kurahashi S, Miyake H (2017) Applicability of scaling relationships of source parameters for crustal earthquakes: examination of ground motion estimation of the 2016 Kumamoto earthquake. Earth Planets Space 69:10. doi:10.1186/ s40623-016-0586-y

Kennett BLN, Kerry NJ (1979) Seismic waves in a stratified half space. Geophys J R Astron Soc 57:557-583

Kitsunezaki C, Goto N, Kobayashi Y, Ikawa T, Horike M, Saito T, Kurota T, Yamane K, Okuzumi K (1990) Estimation of P-and S-wave velocities in deep soil deposits for evaluating ground vibrations in earthquake. J Nat Disaster Sci 9-3:1-17 (in Japanese with English abstract)

Kostrov BV (1964) Selfsimilar problems of propagation of shear cracks. PMM 28:889-898

Lawson CL, Hanson RJ (1974) Solving least square problems. Prentice Hall, Englewood Cliffs

Miyakoshi K, Irikura K, Kamae K (2015) Re-examination of scaling relationships of source parameters of the inland crustal earthquakes in Japan based on the waveform inversion of strong motion data. J Jpn Assoc Earthq Eng 15(7):141-156 (in Japanese with English abstract)

Nakata T, Imaizumi T (eds) (2002) Digital active fault map of Japan. University of Tokyo Press, Tokyo (in Japanese)

National Institute of Advanced Industrial Science and Technology (2012) Active fault database of Japan. Research Information Database DB095. https://gbank.gsj.jp/activefault/index_e_gmap.html. Accessed 30 June 2016

Nelder JA, Mead R (1965) A simplex method for function minimization. Comput J 7:308-313

Okada Y (1992) Internal deformation due to shear and tensile faults in a halfspace. Bull Seismol Soc Am 82:1018-1040

Ozawa T, Fujita E, Ueda H (2016) Crustal deformation associated with the 2016 Kumamoto Earthquake and its effect on the magma system of Aso volcano. Earth Planets Space 68:186. doi:10.1186/s40623-016-0563-5 
Sekiguchi H, Irikura K, Iwata T, Kakehi Y, Hoshiba M (1996) Minute location of faulting beneath Kobe and waveform inversion of the source process during the 1995 Hyogo-ken Nanbu, Japan, earthquake using strong ground motion records. J Phys Earth 44:473-487

Sekiguchi H, Irikura K, Iwata T (2000) Fault geometry at the rupture termination of the 1995 Hyogo-ken Nanbu earthquake. Bull Seismol Soc Am 90:117-133

Shirahama Y, Yoshimi M, Awata Y, Maruyama T, Azuma T, Miyashita Y, Mori H, Imanishi K, Takeda N, Ochi T, Otsubo M, Asahina D, Miyakawa A (2016) Characteristics of the surface ruptures associated with the 2016 Kumamoto earthquake sequence, central Kyushu, Japan. Earth Planets Space 68:191. doi:10.1186/s40623-016-0559-1

Somerville PG, Irikura K, Graves RW, Sawada S, Wald D, Abrahamson N, Iwasaki Y, Kagawa T, Smith N, Kowada A (1999) Characterizing crustal earthquake slip models for the prediction of strong ground motion. Seismol Res Lett 70:59-80

Tada T (1984) Spreading of the Okinawa Trough and its relation to the crustal deformation in Kyusyu. Zisin 2(37):407-415 (in Japanese with English abstract)
Uchide T, Horikawa H, Nakai M, Matsushita R, Shigematsu N, Ando R, Imanishi K (2016) The 2016 Kumamoto-Oita earthquake sequence: aftershock seismicity gap and dynamic triggering in volcanic areas. Earth Planets Space 68:180. doi:10.1186/s40623-016-0556-4

Wald DJ, Helmberger DV, Heaton TH (1991) Rupture model of the 1989 Loma Prieta earthquake from the inversion of strong-motion and broadband teleseismic data. Bull Seismol Soc Am 81:1540-1572

Yagi Y, Okuwaki R, Enescu B, Kasahara A, Miyakawa A, Otsubo M (2016) Rupture process of the 2016 Kumamoto earthquake in relation to the thermal structure around Aso volcano. Earth Planets Space 68:118. doi:10.1186/ s40623-016-0492-3

Yoshida K, Somei K, Miyakoshi K, Ling SQ (2016) Microtremor observations for the strong-motion stations around source region of the 2016 Kumamoto earthquake. In: Proceedings of the 135th SEGJ conference, Muroran Institute of Technology, Muroran, Japan, 26-28 Oct 2016 (in Japanese)

\section{Submit your manuscript to a SpringerOpen ${ }^{\circ}$ journal and benefit from:}

- Convenient online submission

- Rigorous peer review

- Immediate publication on acceptance

- Open access: articles freely available online

- High visibility within the field

- Retaining the copyright to your article 